\title{
University research to touch base with NASA
}

Tony Reichhardt, Washington

NASA centres are being told to reach out to universities in a bid to sharpen their research edge.

As a first step, the space agency is seeking a Californian university to conduct multidisciplinary research and engineering under contract to its Ames Research Center, near San Francisco.

The arrangement is expected to form part of a wider drive by NASA to contract out more of its research and engineering to universities and private companies. New NASA administrator Sean O'Keefe, and the White House Office of Management and Budget $(\mathrm{OMB})$, where he used to work, have each made a public priority of "competitive sourcing" of government activities.

NASA is planning to set up a University Affiliated Research Center (UARC) near Ames, a type of arrangement pioneered by the Department of Defense in facilities such as the Applied Physics Laboratory at Johns Hopkins University in Baltimore, Maryland, in which the centre performs specific research tasks under contract to the sponsor.

The planned centre would focus on areas such as information technology, biotechnology, astrobiology and nanotechnology. Located nearby in a still-to-be-developed NASA Research Park, the UARC would work in close collaboration with what the project's planners call a "lean, civil-servicebased core-research centre" at Ames.

NASA hopes that the mix of university faculty, students and NASA researchers at the centre will draw new talent and stimulate

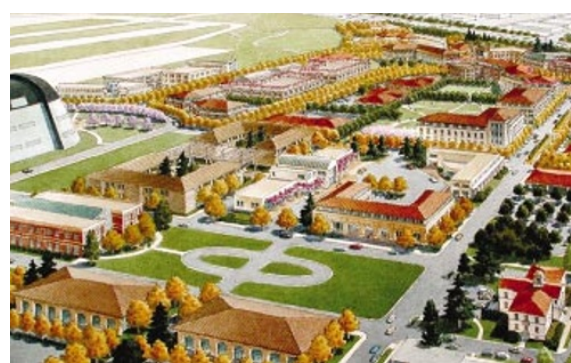

Drawing on expertise: NASA's university-linked centre will be part of its planned research park.

multidisciplinary research and education.

The UARC contract would differ in size and scope from NASA's arrangement with the California Institute of Technology to operate the Jet Propulsion Laboratory (JPL) in Pasadena, California. Whereas the much larger JPL, which has an annual budget of around $\$ 1$ billion, is encouraged to be entrepreneurial and to seek work from sources other than NASA, the UARC would be more tightly bound to its sponsor, and outside work would be limited.

Ames asked for expressions of interest from universities in February. If the idea moves forward as planned, a formal solicitation for a UARC operator would go out in August, with a contract to be awarded next February. The budget for the UARC is estimated at between $\$ 10$ million and \$20 million for the first year, and $\$ 100$ million over a five-year period.

NASA and other federal agencies are under pressure to identify jobs that can be transferred to the private sector. In documents accompanying NASA's 2003 budget request earlier this year, the Bush administration scolded the agency for not going far enough in this regard. The documents identified the Ames UARC as a "pathfinder effort" in outsourcing, and said future efforts "may include consolidating some NASA facilities with military installations."

NASA tried outsourcing some of its inhouse research activities in the mid-1990s, by creating "science institutes" affiliated with universities, but had little success (see Nature 380, 7; 1996). Personnel and management issues have proved particularly thorny whenever the subject of privatizing government research jobs is raised. NASA scientists who transferred last year from the Marshall Space Flight Center in Huntsville, Alabama, to a new National Space Science and Technology Center affiliated with Alabama universities have retained their civilservice status and benefits.

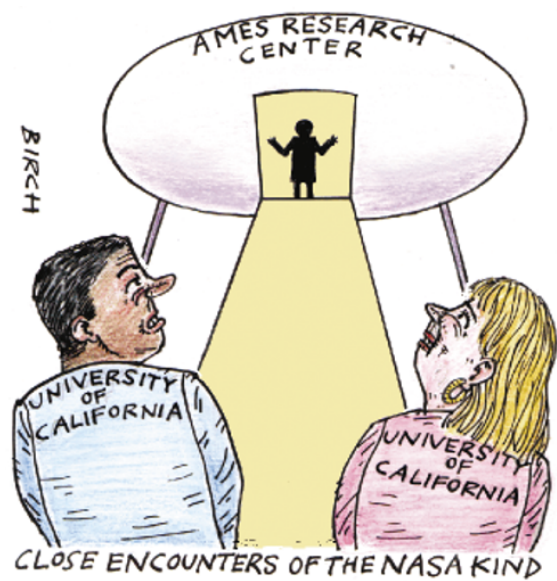

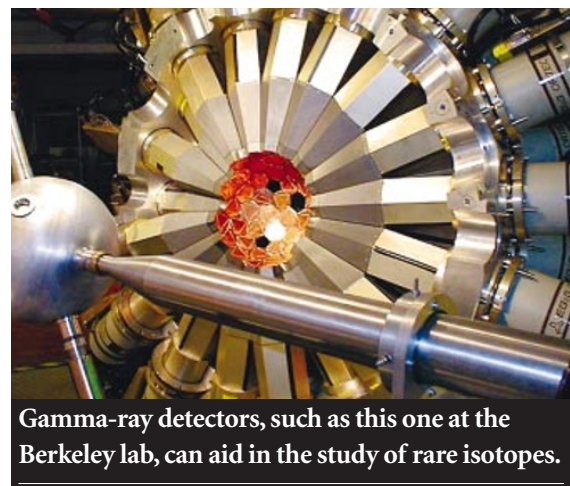

But members of NSAC concede that it will be tough finding money for the two facilities. With its cost estimated at $\$ 700$ million, the RIA would put enormous pressure on the physics budgets of the Department of Energy and the National Science Foundation (NSF).
Even so, says James Symons, chair of the committee and a nuclear physicist at Lawrence Berkeley National Laboratory in California, the country should start thinking about the project now. In the end, Symons thinks, any decision to build the RIA will depend on how the proposal stacks up against desired big projects in other subdisciplines, such as the Next Linear Collider being sought by high-energy physicists.

The NUSL proposal is associated with a site at the Homestake mine in South Dakota (see Nature 415, 105; 2002), and has become an issue in a hotly contested campaign for November's election of a South Dakota senator. But the NSF has responded cautiously to suggestions that it should help to build the NUSL, as this would strain its limited budget for large facilities. "There are great political machinations involved," says
NSAC member Alice Mignerey, a nuclear physicist at the University of Maryland. "But we were very careful that it was the science that drove the recommendation."

Top of the priority list in the 10-year plan, however, is full-capacity operation of the two largest existing nuclear-physics facilities - the Relativistic Heavy Ion Collider at Brookhaven National Laboratory in New York state, and the Continuous Electron Beam Accelerator Facility at the Jefferson Laboratory in Virginia. A proposed $6 \%$ increase in next year's nuclear-physics budget at the Department of Energy would allow that goal to be met immediately, if it is approved by Congress (see Nature 416, 251; 2002). Symons believes that nuclear physicists would then be poised to make some exciting discoveries. "I think this is going to be a great decade for our field," he says. 